\title{
Vivências e sentimentos de profissionais de enfermagem nos cuidados ao paciente sem vida
}

\author{
Experiences and feelings of nursing professionals in caring of the dead patient \\ Experiencias y sentimientos de profesionales de enfermería en la atención al paciente sin vida
}

\author{
Taíse Kuhn', Daniele Delacanal Lazzari", Walnice Jung"II \\ ' Secretaria Municipal de Saúde de Novo Hamburgo, Hospital Regina. Novo Hamburgo-RS, Brasil. \\ " Faculdade Estácio de Santa Catarina, Curso de Enfermagem. Universidade do Sul de Santa Catarina, \\ Curso de Pós-Graduação em Enfermagem. São Jose-SC, Brasil. \\ "II SENAC. Porto Alegre-RS, Brasil.
}

Submissão: 17-10-2010 Aprovação: 04-01-2012

\section{RESUMO}

Este estudo teve como objetivo conhecer as vivências e sentimentos de dez profissionais da Enfermagem em relação ao paciente sem vida, em um hospital privado da região metropolitana de Porto Alegre-RS. Utilizou-se abordagem qualitativa, descritiva, exploratória, com dados coletados em julho de 2009, por meio de entrevista, com questionário semiestruturado. Os resultados foram agrupados nas categorias: sentimentos em relação à morte do paciente, reações à morte e preparo do corpo. Concluiuse que as vivências mais marcantes foram aquelas relacionadas ao primeiro contato com a morte, à presença de vínculos emocionais com pacientes e familiares, e à idade dos pacientes no momento do óbito, sendo estes dois últimos considerados elementos dificultadores dos cuidados oferecidos ao paciente sem vida.

Descritores: Enfermagem; Equipe de enfermagem; Cuidados de enfermagem; Morte; Emoções.

\section{ABSTRACT}

This study aimed to understand the experiences and feelings of ten professional nurses related to the dead patient, in a private hospital of the metropolitan area of Porto Alegre-RS, Brazil. We used a qualitative approach, descriptive, exploratory, with data collected in July 2009, through interviews with semi-structured questionnaire. The results were grouped into the categories: feelings about the patient's death, reactions to the death and preparing the patient's body. It was concluded that the most remarkable experiences were related to the first contact with the death, the presence of emotional bonding with patients and families and the patients' age at death. The latter two are considered hindering elements of care offered to patients without life. Key words: Nursing; Nursing staff; Nursing care; Death; Emotions.

\section{RESUMEN}

Este estudio tuvo como objetivo comprender las experiencias y los sentimientos de diez profesionales de enfermería en relación ao paciente sin vida em un hospital privado en el área metropolitana de Porto Alegre-RS, Brasil. Se utilizó un enfoque cualitativo, descriptivo, exploratorio, con datos recogidos en julio de 2009, a través de entrevistas con cuestionario semi-estructurado. Los resultados fueran agrupados en categorías: sentimientos sobre la muerte del paciente, reacciones a la muerte y a preparación del cuerpo. Se concluyó que las experiencias más notables se relacionan con el primer contacto con la muerte, la presencia de vínculos emocionales con los pacientes y las familias y la edad de los pacientes en la muerte. Los dos últimos se consideran elementos que dificultan la atención ofrecida a los pacientes sin vida.

Palabras clave: Enfermería; Profesionales de enfermería; Atención de enfermería; Muerte; Emociones. 


\section{INTRODUÇÃO}

A equipe de Enfermagem é frequentemente exposta a situações de enfrentamento com a morte de pacientes que estão sob seus cuidados. E, mesmo que façam parte de seu cotidiano de trabalho, tais situações se configuram em momentos em que o manejo dos sentimentos e emoções por parte da equipe parece ser particularmente difícil. Em função disto, por vezes, o paciente que foi à óbito é destituído de todo e qualquer significado e identidade, reforçando a idéia de distanciamento entre profissionais e o corpo sem vida.

Percebe-se que a morte e os cuidados com o preparo do corpo pós-morte são temas pouco discutidos não apenas com os alunos durante sua formação, mas também, com os profissionais da área de saúde em seus locais de trabalho, mesmo com literatura disponível e atual, não se traduz em entendimento prático para o cotidiano dos profissionais. Como consequência, os profissionais da equipe de enfermagem podem apresentar dificuldades para cuidar de forma integral o paciente em sua finitude, limitando-se a cuidar apenas do corpo sem vida e não, necessariamente, do ser humano que morreu.

Este estudo tem por objetivo conhecer as vivências e os sentimentos de uma equipe de enfermagem nas suas relações com o paciente sem vida, durante o processo de preparo do corpo pós-morte, momento este que ultrapassa o procedimento de tamponar um corpo sem vida.

\section{REFERENCIAL TEÓRICO}

A morte pode ser vista de modos distintos, como o fim de um organismo vivo, como um processo social, ou, como um momento de transcendência. Os conceitos ou concepções de morte são variados, porém mantém características entre si, tais como a parada das funções vitais ou a separação do corpo e da alma. A morte, nos séculos passados, era diagnosticada através da cessação da respiração e da função cardíaca. $\mathrm{Na}$ atualidade, o critério utilizado é uma avaliação da função cerebral. A morte também pode ser definida como o estágio final do desenvolvimento humano(1).

Comumente, o morrer não é considerado uma fase do processo de vida, assim como o nascer ou o crescer $^{(2)}$. A morte é, ao menos de maneira consciente, afastada das preocupações do homem do século XXI. Morrer em função da velhice passou a ser considerada a forma natural de morte e todas as outras vão contra a natureza e, por isso, são mortes vistas como desnecessárias ${ }^{(3)}$.

A cultura ocidental transformou a morte em tabu, considerado-a como um momento de fragilidade e vergonha, escondida das crianças e abolida das conversas cotidianas ${ }^{(1)}$. Por isso, o morrer tornou-se hoje um processo solitário, mecânico e desumanizado ${ }^{(4)}$.

Para muitos profissionais da área da saúde, o primeiro contato com a morte é em sala de aula, na disciplina de anatomia, diante do cadáver. Sendo assim, este acaba por ser o primeiro paciente de muitos estudantes. Diante do corpo sem vida, o acadêmico de enfermagem pode se sentir protegido das angústias que a prática direta com doentes ocasiona, embora nesse momento muitos possam sentir-se expostos à angústia que a morte $\operatorname{provoca}^{(5)}$. Mesmo aqueles cujo desempenho acadêmico é considerado satisfatório, acabam por demonstrar atitudes de distanciamento do paciente, sujeito de sua ação, quando em prática assistencial, como se permanecessem cuidando do manequim onde as técnicas de enfermagem lhes foram ensinadas ${ }^{(6)}$.

Para os profissionais da área da saúde a morte faz parte do cotidiano de trabalho, no entanto, estes os profissionais são, não raras vezes, despreparados e apresentam dificuldades para lidar com este acontecimento ${ }^{(7)}$, podendo indicar, na verdade, um despreparo do profissional da saúde, especialmente da Enfermagem, para lidar com a morte de seu paciente, tanto do ponto de vista técnico quanto emocional ${ }^{(8)}$.

Na assistência hospitalar é comum a tentativa de prolongar a sobrevida de pacientes agonizantes, utilizando-se dos mais vários recursos técnicos ${ }^{(4)}$. Nesta tentativa, o profissional da saúde, por valer-se da tecnologia como ferramenta, pode tornar-se distante do paciente fora das possibilidades terapêuticas ${ }^{(5)}$. Nestes momentos, o cuidado se dirige quase que exclusivamente às funções orgânicas, sublimando, por vezes, o envolvimento emocional. Uma relação mais próxima com o paciente que está morrendo poderia remeter o profissional as suas próprias emoções e receios em relação a sua própria morte/vida. Desta forma, foge-se do diálogo com o paciente, bloqueando o processo de amadurecimento e de aceitação da própria morte ${ }^{(4)}$.

Os profissionais que convivem com pacientes fora de possibilidades terapêuticas podem desenvolver respostas específicas, aceitando, elaborando ou mesmo tentando reprimir sentimentos, podendo vir a sofrer de fadiga ou irritabilidade, além de outros problemas, prejudicando, eventualmente, a eficiência no trabalho e/ou interferindo na sua vida familiar. A constatação da morte do paciente pode trazer sensações de impotência e fuga( ${ }^{(9)}$.

Os profissionais da enfermagem são ensinados a cuidar da vida e não da morte, e isso pode ser observado nos cursos na área da saúde onde não existem componentes curriculares que abordem o assunto de forma não defensiva e/ou biologicista $^{(8)}$. Normalmente, as experiências em relação à morte e ao cuidado do paciente sem vida é resultado de um conhecimento adquirido pela prática cotidiana de trabalho, não existindo subsídios qualitativos no que compete às bases de formação de um saber voltado para o preparo frente às situações de morte e morrer ${ }^{(10)}$.

A morte e o processo de morrer são considerados de menor importância, inclusive com relação à imagem que as instituições hospitalares pretendem vincular como sendo um local de cura ${ }^{(11)}$. Vivenciar a morte e ensinar sobre ela é, também, discutir sua omissão na formação profissional, privilegiar a compreensão da limitação temporal da vida, a valorização e objetivos à existência e a separar-se do outro ${ }^{(12)}$. O próprio processo de aprendizagem em relação ao preparo do corpo sem vida deve ser contínuo, independente de ter sido iniciado ou não na formação acadêmica, a fim de preparar emocionalmente quando o exercício profissional assim o exigir ${ }^{(3)}$.

Para a enfermagem, o preparo do corpo morto é classificado como agressivo, doloroso, penoso e muito violento ${ }^{(8)}$. 
Independentemente das emoções vivenciadas pelo profissional diante do momento da morte, o preparo do corpo do paciente que esteve sob seus cuidados e que, dependendo do tempo de internação, pode ter criado vínculos com a equipe, torna-se tarefa árdua. $\mathrm{O}$ corpo sem vida é submetido ao preparo, que possui rituais, com rotinas pré-estabelecidas, normalmente de acordo com a cultura da sociedade e rigor técnico ${ }^{(2)}$. A preparação do corpo pós-morte consiste, dentre outros procedimentos, na retirada dos cateteres, na higienização e nos tamponamentos necessários.

Nas unidades de internação hospitalar em que a morte é uma situação constante, é necessário criar espaços para que a equipe de enfermagem fale de suas tristezas, angústias e possa elaborar seus sentimentos ${ }^{(13)}$. A existência de um espaço para discussões permanentes pode introduzir uma prática que propicie a humanização das relações entre quem cuida e quem é cuidado(11).

\section{MÉTODOS}

Estudo qualitativo, de natureza exploratório-descritiva, realizado numa unidade de internação clínica/cirúrgica de um hospital privado, de médio porte, da região metropolitana de Porto Alegre/RS. A pesquisa teve como objetivo conhecer as vivências e os sentimentos dos profissionais de Enfermagem na relação com o paciente sem vida.

A unidade possui vinte e dois leitos destinados a pacientes conveniados e particulares. A equipe de Enfermagem é composta por quatro enfermeiros e vinte e dois técnicos, divididos em quatro turnos: manhã, tarde, noite I e noite II. A unidade conta com atendimento de uma equipe multidisciplinar, composta por médicos, enfermeiros, técnicos de Enfermagem, nutricionistas, fisioterapeutas e farmacêuticos.

Os critérios para inclusão foram: ser funcionário do hospital há pelo menos um ano; já ter presenciado uma situação de morte e ter realizado o cuidado geral com o preparo do corpo pós-morte; aceitar participar do estudo e assinar o "termo de consentimento livre e esclarecido". Foram excluídos os sujeitos que estavam de férias, folga ou licença saúde.

Participaram deste estudo dez sujeitos que atenderam aos critérios de inclusão e exclusão: quatro enfermeiros e seis técnicos de Enfermagem. A escolha por incluir técnicos de enfermagem e enfermeiros se deu pelo fato de que, embora a rotina de preparo do corpo seja atribuída quase sempre aos técnicos, não é exclusividade do mesmo.

O presente estudo foi encaminhado para o Comitê de ética e pesquisa da Universidade Feevale e aprovado sob o Protocolo $n^{\circ}$ 4.04.03.09.1343. Os aspectos éticos obedeceram à resolução número 196/96 do Conselho Nacional de Saúde, que aprova e regulamenta a pesquisa com seres humanos.

Os enfermeiros foram identificados pela letra $E(E 1, E 2, E 3$ e E4) e os técnicos de Enfermagem pela letra T (T1, T2, T3, T4, T5 e T6).

A coleta de informações foi realizada a partir de um roteiro de entrevista, semi-estruturado, no mês de julho de 2009. As entrevistas foram gravadas em fita cassete e, posteriormente, transcritas para a análise. As informações obtidas nesta pesquisa foram trabalhadas a partir da "análise de conteúdo", segundo Bardin.

\section{RESULTADOS E DISCUSSÃO}

Participaram deste estudo dez sujeitos com idades entre 21 e 38 anos; quatro do sexo masculino e seis do sexo feminino. O tempo de experiência na enfermagem variou de 17 anos a um ano, o tempo de trabalho na instituição em que ocorreu a pesquisa variou entre dois anos e um ano e quatro meses. Dos participantes, nove se declararam católicos e um luterano. Com relação ao turno de trabalho, quatro participantes trabalhavam no período diurno e seis, no período noturno.

\section{Sentimentos em relação à morte do paciente}

Quando questionados sobre sentimentos com relação à morte, os sujeitos relataram o significado da "primeira morte" para o profissional da saúde.

Ela tava na UTI conversando conosco e pediu banho. Os colegas não puderam me ajudar. Eles me informaram que precisava que ser com muita calma. Quando eu terminei o banho ela disse: não estou me sentindo bem. E eu me apavorei. E os colegas vieram e iniciamos as manobras. $O$ médico ficou 40 minutos investindo e disse que não tinha mais nada a fazer. Me apavorei... T1

Os demais entrevistados também referiram momentos importantes associados à primeira perda, no entanto, o fizeram esclarecendo que o impacto se deu a partir da vinculação existente com o paciente. Para alguns, a idade é fator fundamental, para outros, a forma como o processo da morte se deu.

...criança, principalmente. Vivenciei a morte de uma criança uma vez. De 3 anos. De toda equipe não teve quem não chorasse com a emoção. Depois que a mãe chegou. Vendo o desespero. A criança foi atropelada. Então foi bastante chocante... E3

... um que vi morrer na minha frente, de hemorragia digestiva alta, que jorrava sangue. Se batia na parede próxima à cama. Em questão de segundos ele veio a falecer. E1

Os sujeitos entrevistados demonstraram sentimentos ambivalentes de impotência e onipotência, sentindo que as expectativas do paciente, família, colegas são arremessadas sobre eles e, para suportarem, muitas vezes, se refugiam em suas defesas, no racionalismo, no não envolvimento ${ }^{(14)}$. Assim, surge o sentimento de impotência, pois não foi possível, naquele momento, evitar ou adiar aquela morte e, podem ocorrer crises existenciais e profissionais, pois os limites da profissão e da vida humana são constantemente desafiados.

... uma pessoa que tá aí e não tinha mais o que fazer ... E1

Os depoimentos também parecem apontar para um sentimento de culpa, pois alguns dos entrevistados parecem 
acreditar que não trataram o paciente da melhor forma e com isso não puderam evitar a sua morte, de que poderiam ter feito melhor para dar conta desta tarefa.

... às vezes me indago sobre o que poderia ter feito mais para evitar que isso acontecesse ... E2

... de vez enquanto fica aquele vão. O que poderia ter feito para ele para isso não ter acontecido... tudo que eu fiz, o que eu poderia ter feito a mais, o que eu não fiz. Fica aquela lacuna... E4

... eu acreditei que havia matado a paciente ... T1

É possível perceber nas falas dos sujeitos as atitudes de proteção do ser humano frente a situações com as quais não sabe lidar, como a morte, a fim de não vivenciar sentimentos considerados incômodos, tais como a sensação de fracasso por não ter conseguido fazer algo para evitar um desfecho, mesmo diante de sua inevitabilidade ${ }^{(1)}$.

Está envolvida, ainda, neste processo, a identificação do indivíduo ao se colocar no lugar do outro e, com base em suas próprias suposições ou impressões, tentar compreender o comportamento do outro, sofrer o que ele sofre ${ }^{(15)}$. Para tanto, a empatia pode ser definida como uma habilidade social constituída de três componentes: o cognitivo, o afetivo e o comportamental. O primeiro consiste na capacidade de adotar a perspectiva dos demais e entender seus pensamentos e sentimentos. O segundo é caracterizado por uma predisposição para experimentar compaixão e preocupação com o bem-estar das outras pessoas. E o terceiro traduz-se pela habilidade de expressar compreensão e reconhecimento para com os sentimentos e pensamentos de outrem ${ }^{(16)}$

As reações de perda que os profissionais de Enfermagem podem ter ao longo da vida, em nível físico, emocional, social e espiritual variam de pessoa para pessoa e dependem dos fatores que permeiam o momento da morte do paciente: tipo de relação que existia entre ambos e qualidade dos mecanismos de defesa utilizados ${ }^{(2)}$. Há o sentimento de frustração no momento da perda, pois há o desejo de ver a melhora clínica e a evolução do paciente e não presenciar a sua morte, que é, por vezes, sentida como uma derrota profissional.

...logo que tu começas, tu sentes um pouco frustrado nesse momento. Porque você entra nesta profissão tentando ajudar as pessoas. De certa forma, vê a evolução, a melhora. Então esse momento é meio frustrante... T3

A tristeza é um sentimento presente em função do envolvimento emocional. Pode-se perceber na descrição abaixo, que independente da afinidade que o enfermeiro tenha com o paciente ou com a família, o sentimento de tristeza é inevitável.

...não tem o que fazer, é um processo natural, o sentimento de tristeza. Eu, particularmente, fico triste.... E4
Há ainda, relatos sobre o sofrimento de cuidar do paciente após a sua morte, trazendo a questão da fugacidade da vida. Tratar o corpo como se o paciente ainda estivesse vivo, pode ser visto como um cuidado humanizado.

...eu me sinto bem desconfortável no preparo do corpo do paciente. Porque instantes antes, estava ali, fazendo o atendimento. $E$, em outro instante, logo depois, ele foi a óbito. É complicado separar o antes e o depois. T5

Sendo assim, advêm dificuldades em oferecer apenas um cuidado procedimental em um momento em que há envolvimento emocional, sendo difícil não externar os seus sentimentos diante da morte expressa num corpo sem vida ${ }^{(17)}$.

\section{Reações frente à morte}

Percebe-se a necessidade da Enfermagem em desenvolver mecanismos de defesa e enfrentamento frente à morte do paciente e ao cuidado pós-morte. Os profissionais utilizam-se de vários mecanismos de defesa no enfrentamento das situações de morte e no preparo do paciente sem vida na tentativa de minimizar seu sofrimento. Estas manobras psíquicas são necessárias, pois os profissionais são preparados para a manutenção da vida, e o processo que compõe a morte o morrer parece se constituir na exceção, naquilo que parece não estar presente em seu contexto de cuidar ${ }^{(10)}$.

Neste ponto, é importante salientar que os mecanismos de defesa são processados pelo ego e são, na maioria das vezes, inconscientes ${ }^{(13)}$. Percebe-se como os profissionais tentam o distanciamento e evitam contato com o paciente que acabou de falecer e seus familiares.

Acredito que se pudéssemos evitar ou ao menos distanciar-nos, não participaríamos daquele momento em específico. Acredito que os profissionais querem resolver tudo com a maior brevidade ou rapidez possível e que tudo se resolva prontamente. E2

...em relação ao preparo do paciente depois que este morreu, não foram muitos conflitos, geralmente estava com os outros colegas e tentava não participar ativamente dos cuidados, era mais na solidariedade aos colegas que eu fazia alguma coisa. Mas, normalmente, evitava. T2

Ocupados com as rotinas a serem seguidas, alegaram familiaridade com os cuidados com o corpo sem vida, banalizando a necessidade de lidarem com os próprios sentimentos.

...gera desconforto. É a morte! Então tu acabas agindo de forma mais mecânica. É mais fácil. E1

Eu acredito que é automático. Já estamos tão acostumados com aquilo, que acabamos agindo automaticamente, quase como robôs, mecânicos. T2

$\mathrm{Na}$ tentativa de se protegerem e não vivenciarem sentimentos que possam Ihes produzir alguma desestabilização 
emocional, os profissionais assumem comportamentos de distância e frieza.

...tu tens que, digamos, te tornar uma pessoa um pouco fria. Se tu és muito sentimental, acabas ficando muito sem ação e é um momento em que tu tens que agir... E1

Os sujeitos utilizaram palavras como 'fria' ou "frieza", para afirmar que, se não estiverem distantes da situação, será impossível conceber os cuidados. Discutem, também, a questão da 'agilidade', precisando ser 'frios' para se tornarem 'ágeis'. Este comportamento manifestado é considerado uma necessidade para o exercício do trabalho e na sua ausência, parece não ser possível exercê-lo.

Existem ainda, em muitos ambientes hospitalares, regras explícitas ou implícitas sobre o não envolvimento emocional daquele que é considerado bom profissional. Desta forma, não encontrando espaço para expressar sua angústia e fraqueza, há espaço para a negação e sublimação de sentimentos. Por isso, se faz presente a necessidade do desenvolvimento de mecanismos de defesa como os expressos pelos sujeitos desta pesquisa, de manterem-se emocionalmente distantes frente às situações ou, então, em equilíbrio, ao menos aparente, na tentativa de manejar a situação da forma considerada a mais adequada possível.

Eu procuro não deixar me abalar pela morte do paciente. É inevitável. Todos, um dia, vão ter que chegar nesse momento... T3

Hoje eu estou preparado, porque consegui separar o lado sentimental do lado profissional e do pessoal... E1

Nunca vamos dizer que estamos preparados para lidar com a morte. Vou para casa e esqueço. Geralmente, saio do hospital e já esqueço. E3

Percebe-se o uso da racionalização na tentativa de suportar o contato com a morte e manter o ajustamento emocional, além do controle da ansiedade, apresentando justificativas aparentemente lógicas e racionais, aceitáveis para uma atitude, ação ou sentimento gerador de angústia ${ }^{(19)}$.

A idade do paciente parece ser a característica expressiva, pois representa o entendimento de que há potencialidade em alguém de vir a contribuir com a sociedade. Isso implica na concepção de que a morte de um jovem representa uma perda tanto para a família quanto para a sociedade ${ }^{(11-13)}$. Os sujeitos entrevistados consideram mais penoso se depararem com crianças e jovens em processo de morrer, além das mortes consideradas bruscas e/ou inesperadas.

... quando o paciente é mais jovem, imaginamos o quanto o paciente poderia ter vivido ainda... T6

...eu também trabalhei na emergência, aonde chegavam muitos pacientes jovens. O que me marcou muito foi um paciente baleado, que morreu e não estava doente... E3
Há ainda a distinção feita pelos participantes em relação à morte de crianças, pois estas despertam sentimentos de ternura e o desejo de proteção. Deste modo, o paciente pediátrico torna ainda mais difícil o uso dos mecanismos de defesa já mencionados, deixando o profissional mais vulnerável aos sentimentos.

...quando é criança acabamos sentindo mais. Familiares juntos, chorando. Você acaba se comovendo também. Acaba ficando mais machucado. Mas devemos agir com naturalidade. $T 2$

A faixa etária do paciente é determinante no enfrentamento da morte, é percebida como traumatizante para a equipe quanto mais jovem ele for ${ }^{(8)}$. No caso de idosos, a idade parece constituir-se em atenuante de tal percepção.

...se é um idoso, acabamos ficando mais conformados. Não sente tanto. Parece que o tempo passa. E parece que perdemos um pouco... sempre sentimos algo triste, mas não dá mesma forma, já que cumpriu seu ciclo, morreu... T2

...se é um paciente de mais idade, tenho outro entendimento. Mas depende também se a morte já era esperada ou foi inesperada... T6

Fica evidente nos depoimentos que a morte do idoso pode não ser considerada tão dolorosa, pois o próprio paciente pode estar em sofrimento em função da debilidade das funções corporais próprias do processo de envelhecimento.

No entanto, as dificuldades para enfrentar a morte estão fortemente presentes quando esta ocorre com um colega de profissão, membro da equipe de enfermagem ou familiares dos entrevistados, em função de os vínculos existentes serem mais estreitos, pelas mais diversas razões proporcionadas pelas formas de convivência. Nestes casos, o tempo de experiência na enfermagem não facilita o enfrentamento e a vivência é sempre traumática, falhando, por vezes, os mecanismos de defesa e proteção, e originando intenso sofrimento.

Teve um paciente em especial que me marcou bastante... Foi uma colega minha. Foi algo que, por mais tempo de experiência que eu tenha, nunca esperava passar. Foi muito difícil. T3

.. ela [colega de trabalho] mesma veio no ambulatório em que eu trabalhava dizendo que não sentia-se bem. Deitou na maca sozinha. Quando ela disse 'vou morrer' e em seguida, morreu... E1

De acordo com os depoimentos, é mais uma vez possível confirmar que o enfrentamento e as reações do profissional dependem em grande parte do vínculo preexistente com o paciente ou seus familiares, além da idade e da natureza da morte.

...cada paciente é diferente. Tem alguns que nos envolvemos mais intensamente, por conhecer há mais tempo, pela 
história de vida se for uma doença crônica, pela idade. Então, acaba-se tendo um vínculo maior. T4

...depende do tipo de paciente... Porque têm pacientes que, desde o início da internação, já esperamos pela morte, nos preparamos antecipadamente porque sabemos que aquele paciente está para morrer. E3

\section{O preparo do corpo}

Os cuidados de Enfermagem ao paciente sem vida compreendem os aspectos técnicos, tais como a retirada dos cateteres, os tamponamentos e a higienização do corpo; momento este que pode ser compreendido como agressivo e penoso, pois não há preparo emocional para vivenciá-lo ${ }^{(19)}$. Nas falas dos sujeitos desta pesquisa, evidencia-se a inexistência de preparo e a busca por concluir o procedimento de forma mais rápida possível.

... Queremos o quanto antes ficar livres destes procedimentos com o corpo morto. Temos que parar com nossas atividades e ir tamponar. É um pouco estranho... E complicado. T2

A preparação do corpo pela equipe de enfermagem deve compreender os últimos cuidados referentes à higiene, curativos e tamponamentos de orifícios corporais. Raramente é necessário banhar o paciente que acabou de falecer, porém, é necessário limpar as marcas de sangue ou secreções e realizar curativos compressivos em incisões. Os orifícios merecem uma atenção especial, pois seu preenchimento com algodão em excesso pode desfigurar as feições. O tamponamento deve ser feito nas primeiras horas após a confirmação do óbito ${ }^{(19)}$.

Os sujeitos desta pesquisa mencionam o desconforto e tristeza presentes no momento do procedimento, mas também demonstram respeito por aquele corpo que há pouco tempo era cuidado de outra forma.

...o preparo, a retirada de objetos, os materiais que são utilizados, oxigênio, sondas, coisas do tipo, isso é desconfortável. Tem os processos invasivos mesmo no corpo morto, enfim ... E1

O que eles informaram no curso é que precisávamos cuidar do corpo, que se precisasse de banho, teríamos que fazer e depois, tamponar. Informaram que precisávamos ter respeito na hora, não fazer piadas e permanecermos em silêncio. A minha primeira experiência com morte foi como estagiária, não soube o que fazer, simplesmente fiquei quieta, observei a professora e fui tamponando [...] T1

É possível compreender em alguns depoimentos, a importância do respeito no momento do preparo do corpo do paciente que acabara de falecer. Além de identificar que, na concepção dos participantes desta pesquisa, o respeito ao corpo não é realizado por todos os profissionais de Enfermagem, de acordo com as próprias vivências.
... Percebo que as pessoas parecem ser frias, distantes. Eu continuo respeitando aquele corpo como se fosse uma pessoa ainda viva, presente. Mas percebo que muitos não tem essa mesma conduta. Às vezes fazem brincadeiras, não respeitam ... E2

... Existem profissionais que, apesar de formados nas áreas da enfermagem, não gostam da profissão. Então, às vezes, você ouve alguma brincadeira. E, neste momento, não podemos brincar. T1

A conduta desejável para a equipe de Enfermagem diante do corpo do paciente sem vida, independentemente da presença dos familiares, deve ser de respeito, evitando brincadeiras ou conversas sobre assuntos externos ao cuidado que está sendo oferecido(8).

\section{CONSIDERAÇÕES FINAIS}

Esta pesquisa procurou compreender os sentimentos dos técnicos(as) de Enfermagem e enfermeiros(as) na relação com o paciente sem vida numa unidade de internação de um hospital privado de médio porte da região metropolitana de Porto Alegre-RS.

Foi possível compreender que, dentre os sentimentos que estes profissionais experimentam diante da morte e do cuidado ao paciente que acabou de falecer, a empatia merece lugar de destaque no grupo pesquisado, pois referem colocar- se no lugar do outro e ainda, oferecer algum cuidado aos pais, irmãos, filhos e demais familiares. Também foi observado um dualismo entre impotência e onipotência em relação à situação de morte do paciente, bem como culpa e frustração por não conseguirem alcançar a melhora do indivíduo sob seus cuidados ou mesmo evitar sua morte. Por fim, surge o sentimento de tristeza, mediada pelo grau de afinidades com o paciente.

As vivências mais marcantes envolvendo a morte de paciente situaram-se entre as relacionadas à primeira morte. Além disso, outras também foram enfatizadas, como a vinculação com o doente e sua idade. Boa parte dos sujeitos entrevistados demonstrou dificuldade em aceitar a morte de uma criança ou jovem, enquanto a morte de um idoso é considerada de mais fácil assimilação.

Percebe-se que os profissionais da Enfermagem necessitam de estratégias para o enfrentamento das situações causadoras de estresse e desestabilização emocional, tais como a morte do paciente. Para alguns, a religiosidade e/ou espiritualidade foi considerado aspecto fundamental. Outro modo de enfrentamento referenciado foi a mecanização e despersonalização do cuidado, destituindo-o de qualquer outro significado. Além disso, foram relatadas situações de distanciamento e racionalização no momento da morte do paciente.

No grupo pesquisado, verificou-se a falta de preparo da equipe de Enfermagem em relação ao preparo do corpo sem vida. Foi possível identificar que nem todos os profissionais sentem-se preparados para lidar com a morte e com o procedimento denominado tamponamento. Provavelmente, de 
forma defensiva, a compreensão deste procedimento fica restrita ao plano meramente técnico.

Verificou-se também que idade, sexo, tempo de profissão, experiência, religião e turno de trabalho não se mostraram como elementos significativos nas percepções manifestadas pelos entrevistados. Pode-se afirmar que os sentimentos e vivências dos entrevistados foram comuns a todos.

Os participantes desta pesquisa enfatizaram a importância de capacitação para que possam lidar com este momento, tornando a assistência de enfermagem verdadeiramente integral ao paciente, à família e à própria equipe de Enfermagem. O trabalho em equipes multiprofissionais poderia subsidiar as ações tornando o atendimento ainda mais enriquecedor.

Assim, este estudo permitiu compreender como um grupo de profissionais da enfermagem enfrenta a morte e como reagem neste momento em função das relações construídas com os pacientes, seus familiares e entre a própria equipe. Evidencia-se, por fim, a importância que a Enfermagem possui neste momento especial do cuidado, que, não raras vezes, deixa marcas nas vidas profissionais dos envolvidos.

\section{REFERÊNCIAS}

1. Bernieri J, Hirdes A. O preparo dos acadêmicos de enfermagem brasileiros para vivenciarem o processo morte-morrer. Texto Contexto Enferm. 2007;16(1):89-96.

2. Ribeiro MC, Baraldi, S, Silva MJP. A percepção da equipe de enfermagem em situação de morte: ritual do preparo do corpo "pós-morte". Rev. Esc. Enferm. USP. 1998;32(2):117-23.

3. Bellato R, Carvalho EC. O jogo existencial e a ritualização da morte. Rev. Latino-Am Enfermagem. 2005;13(1):99-104.

4. Brandão L. Psicologia hospitalar: uma abordagem holística e fenomenológico-existencial. Campinas: Livro Pleno; 2000.

5. Nova JLL, Filho JJB, Bastos LAM. Lição de anatomia. Interface. 2000;4(6).

6. Reinaldo MAS. O pacote de emoções geradas pelo ensino da técnica de preparo do corpo pós-morte: relato de experiência. Ver. Eletr. Enf. [Internet].2005 [cited 2009 ago 21]; 07(1):95-98. Available from: http://www.fen.ufg. br/revista.htm

7. Kovács MJ. Morte e desenvolvimento humano. São Paulo: Casa do Psicólogo; 1995.

8. Figueiredo, NMA. Ensinando a cuidar em saúde pública. São Caetano do Sul: Yendis Editora; 2005.

9. Brêtas JRS, Oliveira JR, Yamaguti L. Reflexões de estudantes de enfermagem sobre morte e morrer. Rev. Esc. Enferm. USP. 2006;40(4):477-83.

10. Susaki TT, Silva MJP, Possari JF. Identificação das fases do processo de morrer pelos profissionais de enfermagem. Acta paul. enferm. 2006;19(2):144-49.

11. Gutierrez BAO, Ciampone MHT. O processo de morrer e a morte no enfoque dos profissionais de enfermagem de UTIs. Rev. Esc. Enferm. USP.2007;41(4):660-67.

12. Bellato R. et al. A abordagem do processo do morrer e da morte feita por docentes em um curso de graduação em enfermagem. Acta paul. enferm. 2007;20(3):255-63.

13. Shimizu HE. Como os trabalhadores de enfermagem enfrentam o processo de morrer. Rev. bras. enferm. 2007;60(3):257-62

14. Angerami-Camon VA. Psicologia hospitalar: teoria e prática. São Paulo: Pioneira, 2009.

15. Moreira V. Da empatia à compreensão do lebenswelt (mundo vivido) na psicoterapia humanista-fenomenológica. Rev. Latinoam. psicopat. Fund. 2009;12(1):59-70.

16. Motta DC. et al. Práticas educativas positivas favorecem o desenvolvimento da empatia em crianças. Psicol.est. 2006;11(3):523-32.

17. Nascimento MAL. et al. O cuidado de enfermagem com o corpo sem vida. Texto Contexto Enferm. 2007;16(1):168-71.

18. Silva CAB. et al. Ambiguidade genital: a percepção da doença e os anseios dos pais. Rev. bras. saúde mater. infant.. 2006;6(1):107-13.

19. Veiga DA, Crossetti MG. Manual de técnicas de enfermagem. Porto Alegre: Sagra Luzzatto, 2000. 